\title{
Towards a Roadmap for User Involvement in E-Government Service Development
}

\author{
Jesper Holgersson $^{1}$, Eva Söderström ${ }^{1}$, Fredrik Karlsson ${ }^{2}$, and Karin Hedström ${ }^{2}$ \\ ${ }^{1}$ University of Skövde, Högskolevägen, SE-541 28 Skövde, Sweden \\ \{eva.soderstrom, jesper.holgersson\} @his.se \\ ${ }^{2}$ MELAB, Swedish Business School at Örebro University, SE-701 82 Örebro, Sweden \\ \{fredrik.karlsson, karin.hedstrom\}@oru.se
}

\begin{abstract}
New technology means new ways of both developing, providing and consuming services. In the strive for government organizations to build and maintain relationships with its citizens, e-presence is highly important. Eservices are one way to go, and it has been argued that user participation is an important part of developing said services. In this paper we analyze a selection of user participation approaches from a goal perspective to see how they fit in an e-government service development context., In doing so, we identify four challenges that need to be addressed when including users in the development: 1) Identifying the user target segment, 2) Identifying the individual user within each segment, 3) Getting users to participate, and 4) Lacking adequate skills.
\end{abstract}

Keywords: E-services, E-government, E-service development, User participation.

\section{Introduction}

New technology enables a broadened choice of how to deliver services, and electronic services (e-services) have become an increasingly adopted channel [1]. Today, this channel is an important part of implementing e-government strategies. When eservices are introduced as part of the e-government concept they are often viewed as a way to automate internal, manual, processes [2]. In other words, they are driven from the government perspective, and user considerations have been given less attention.

Recent studies [3] have shown that increased attention to users' (citizens, public authorities, or businesses using the e-service) needs bring positive effects when eservices are deployed. This confirms earlier research about user involvement [4] and is not surprising. User involvement has been treated extensively in information systems (IS) literature [4], and there are several well known approaches, such as Participatory Design (PD) [5], User Centered Design (UCD) [6] and User Innovation (UI) [7]. Each of these can be viewed as a design theory [8], with associated design principles or design goals, for how to take users' needs into consideration during development. However, as discussed by [9] and [10] these theories are introduced in new settings as the information systems field moves forward, settings that was not considered when the theories evolved. Consequently, e-service development can be 
viewed as such a new setting. It is therefore natural to investigate if it is possible to apply them when developing e-government services. This paper aims to analyze the three mentioned user participation approaches in e-government service development from a goal perspective, in order to identify challenges for user participation in development. Awareness of the challenges is important in order to increase citizen inclusion, as well as the chances of mutual gain from development. Inclusion may also increase democratic principles, and enable the development of more usable and valuable e-government services.

The paper is structured as follows. In the second Section we outline our research design and analytical framework. In the third Section we identify requirements on egovernment service development. Sections four and five contain the analysis, where we map the requirements to the goals behind the user participation approaches. Finally, the paper ends with short conclusions concerning the challenges identified and reflections on future research.

\section{Research Design}

In this paper we view user participation approaches from a design science perspective [11], where each approach represents a design theory. This means each approach has been devised through a goal-oriented design activity [12], where certain design goals were set out. Hence these design goals or principles tell us what can be achieved with that particular approach, which can be compared with the requirements that are found about e-government service development. To achieve this end we need an analysis framework that can reconstruct the design principles of each design theory. Therefore, we have chosen the framework laid out in [13] to analyze the rationale, or the goals, behind each approach.

The framework in Fig. 1 is depicted as a Unified Modelling Language-class diagram. It consists of three classes: method fragment, goal and values, and between these we find a number of named associations. The method fragment concept refers to a description of a systems development method, or any coherent part thereof [14]. According to [15] method fragments can be studied on five different levels of granularity: method, stage, model, diagram, and concept. Method addresses a complete method for systems development, for example, Rational Unified Process. Concept on the other hand is the smallest part of a method, representing a single construct in the method.

Each method fragment is anchored in goals and values. These are often referred to as the method's perspective [16] or argumentative dimension [17]. Goals reflect the method designer's intentions with the method, what that the method user will be able to achieve when using it - in other words, the design goals. Since a method can have several goals, these goals can either support or contradict each other. In addition, a goal is based on one or more values, which are ideals held by the method designer. The principle about achievement and contradiction applies here as well, where values in a method can support or contradict each other. 


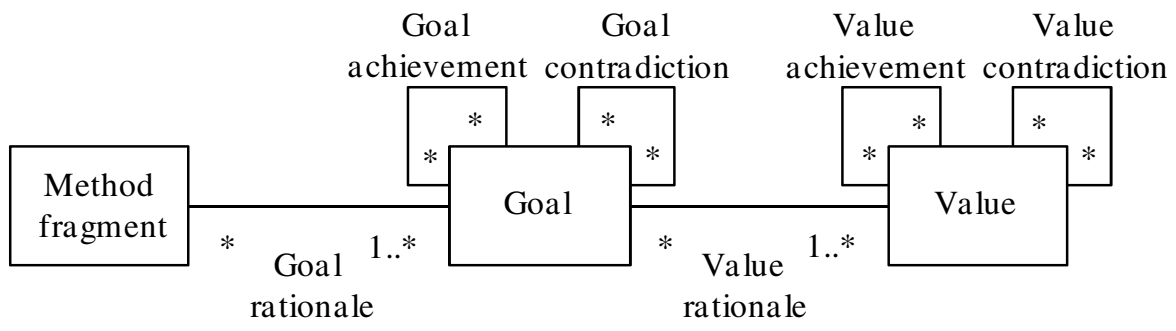

Fig. 1. Method rationale framework [13]

Our data analysis was done in three steps, where the last two steps form an iterative pattern. The first step concerns elicitation of the requirements of e-government service development. This step is based on existing research on e-government service and was presented in Section 2. The second step, presented in Section 4, consists of a reconstruction of the design goals behind each of the selected user participation approaches. In order to make the methods more comparable we have used goals graphs, using a unified notation, inspired by $\mathrm{Yu}$ [18]. We have selected goals put forward as important in literature. As we are interested in the challenges to fulfil these goals we have decided not to include values in the analysis. Subsequently, we do not question the goals and the values as such, rather investigating the problems of fulfilling them in an e-government service development context.

All methods consist of a large number of goals if the analysis is done at a low granularity level. However, since we are interested in a strategic discussion concerning the applicability of these approaches we view the selected approaches as one stage in a development method. According to Brinkkemper's [15] typology of method fragments, a stage addresses "a segment of the life-cycle of the information system," for example, design. Therefore, we have investigated high-level goals to see how well they support the requirements of e-government services development.

The third step focuses on analysing the possibilities to fulfil the goals that we have identified for each user participation approach. In Section 5, we have mapped the identified requirements to the design goals. With this basis we have identified challenges with meeting certain requirements.

\section{E-Government Service Development}

Many governments wish to improve their service to citizens and companies by becoming more flexible in a dynamic and changing environment [19]. Today, webbased technologies, such as e-services [1, 20], offer new opportunities for governments to communicate with citizens and businesses. These technologies are efficient alternatives to the traditional physical channels. But development of egovernment services is a complex endeavor. Many of these services have to be offered more all less universally to all citizens [21] in order to fulfill normative values such as democracy and individual human rights. Hence, identifying relevant 
e-government services and eliciting valid systems requirements for these broad target groups are challenging [22]. Also, development often includes integration of different government entities, which results in complex solutions [23].

Normative and legal values are embedded in the actions performed by public administrations [24]. For example, in Sweden they are referred to as a "public ethos" that shall govern the actions of the civil servants. The public ethos is based on democracy and human rights, striving for the legal rights of the individual [25]. As egovernment concerns the development of information systems (IS) for the public sector, the IS supporting e-government services, should be developed with particular attention to the values and goals related to the public ethos, such as using ICT as a tool to support increased citizen participation in democratic processes [2, 26]. Business values are also included in the Swedish public ethos [25], meaning that public administrations should take into account economic values such as functionality, productivity and efficiency [27, 28].

Development of e-government services has, as mentioned, traditionally focused on automating internal manual business processes [2]. Attention has been on possible efficiency generated by the e-service, and not on users [29]. At best, user needs have been guessed and not thoroughly analyzed [30]. However, the role of the user is now shifting towards active user participation in various forms [31]. It is evident that active user participation increase the likelihood of positive effects on service use, not only from the providing authority's point of view but also from the user's [32, 33]

Table 1. Requirements on e-government service development

\begin{tabular}{ll}
\hline Requirement & References \\
\hline To develop e-services that are relevant to the users & {$[21,22]$} \\
To develop e-services that are useable & {$[29,30,32,33]$} \\
To develop e-services that are efficient for the government & {$[2,25,27,28]$} \\
To develop e-services that supports democracy & {$[2,25,26]$} \\
To employ an efficient and democratic development process for & {$[25,27]$} \\
the government & \\
\hline
\end{tabular}

To summarize, the interest for applying user participation approaches in egovernment service development is growing. At the same time we can also identify (at least) five requirements that are important during development of e-government services. These requirements, which are central to the analysis in this paper, are summarized in Table 1.

\section{User Participation Approaches}

There are numerous approaches for how to incorporate users in the development process. A closer look at these approaches reveals many shared characteristics. In this paper, we focus on three such approaches: Participatory Design (PD), User Centered Design (UCD), and User Innovation (UI). We have chosen these three approaches for two reasons; (a) they are commonly mentioned in research literature; and (b) they are 
focused on user participation, but from different perspectives. The analysis maps out, and relates, the design goals of each approach, which enables comparison of the three. Each goal is first given a design approach identifier (PD, UCD and UI respectively), and then a goal identifier (G1, etc.)

\subsection{Participatory Design}

PD represents " $a$ rich diversity of theories, practices, analyses, and actions, with the goal of working directly with users (and other stakeholders) in the design" [34pp. 25]. The overall goal is usable and accepted ICT systems (PD-G1 in Fig. 2). PD stems from basic democratic principles: people affected by a decision or change should be able to influence it (PD-G2). Another important PD aspect is that users or user representatives (PD-G3) must actively contribute (PD-G4) in analysis, design, prototyping and implementation of an information system [35]. Furthermore, the importance of designers and users working together is emphasized [5] (PD-G5). Both roles are equally important and must take responsibility for the project outcome. The designer needs knowledge about the information system setting (PD-G7) and the user needs knowledge about technical possibilities and restrictions (PD-G6). Kensing \& Blomberg [35] state three basic PD requirements, the users must: have access to relevant information; have the possibility to take an independent position to the problem dealt with; and participate in decision making.

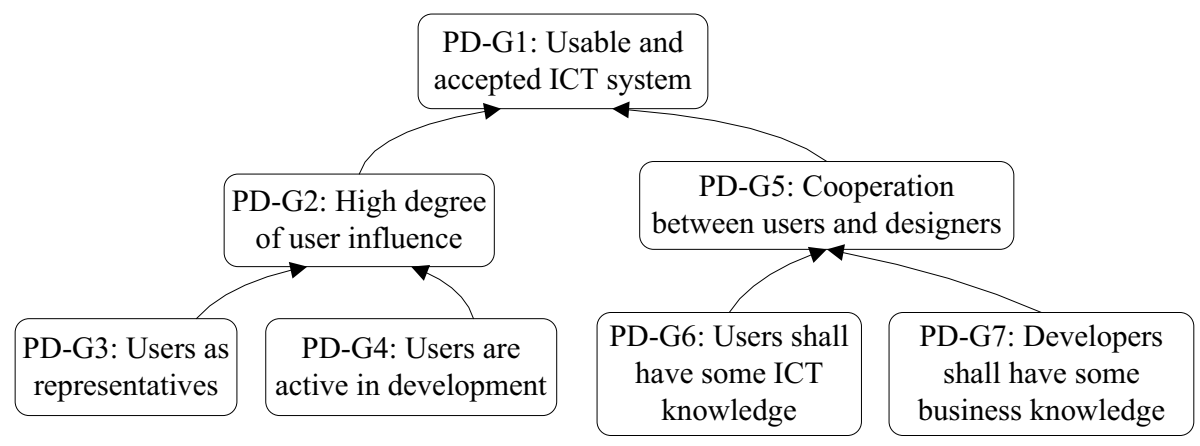

Fig. 2. Goal analysis for Participatory Design

\subsection{User Centered Design}

UCD emphasizes that the system purpose is to serve the user, not to use a specific technology or be an elegant piece of programming [6]. User environments must therefore be understood and considered when designing systems [36]. In Fig 3, we express this as UCD-G1. Better user theories will allow designers to build more usable interfaces and systems [37]. Work organization must hence be analyzed beyond traditional task analysis to incorporate social and organizational contexts that influence the users' operations [37]. The user needs should dominate the interface design, and the interface needs should in turn dominate the remaining systems design 
[6]. This is illustrated as UCD-G2 in Fig. 3. From the beginning, UCD did not involve users actively even though user needs were imperative. Now, user participation is essential in the early project phases, with a focus on requirements analysis [38]. If users are to have any impact, they must provide information that is appropriate to particular stages of the development. Developers therefore need extensive business knowledge (UCD-G5). User participation for partially finished products is only worthwhile if changes and modifications can be made at this stage [38]. It is, however, possible to include users to assess if user requirements are met. In summary, in UCD, users are rather passive and act as advisors, only having moderate influence on the development per se (UCD-G4); thus designers have the design responsibility (UCD-G3).



Fig. 3. Goal analysis for User Centered Design

\subsection{User Innovation}

UI is focused on innovations made by users. As shown by UI-G1, in Fig. 4, the overall goal is to provide 'innovative systems functionality.' Users are the source for innovation and design rather than organizations, [7, 39]. UI is based on the concept of lead users that capture ideas (UI-G2), which are transformed into full-blown solutions in collaboration between users and developers (UI-G5). Typically, lead users are the ones who perform product and service innovations; they identify the problems (UIG3) as well as the design solution (UI-G4). A lead user is considered to be a user of a certain application or product [39].

Using lead users in design differs from other approaches in the sense that the lead users themselves try to design products and services that satisfy their needs. Subsequently, they are responsible for problems and solutions (UI-G6). This means that lead users own the design, even if developers build the solution (UI-G7). This may lead to innovative ideas and solutions compared to other approaches, since lead users are free from the limits of regular designers. Focusing on typical users, rather than lead users, is not optimal when working with fast moving fields such as IS, were time of development may result in obsolete applications and products. In this case working with lead users to identify novel needs that have not yet been discovered by the general public may prove to be beneficial $[7,39,40]$. 


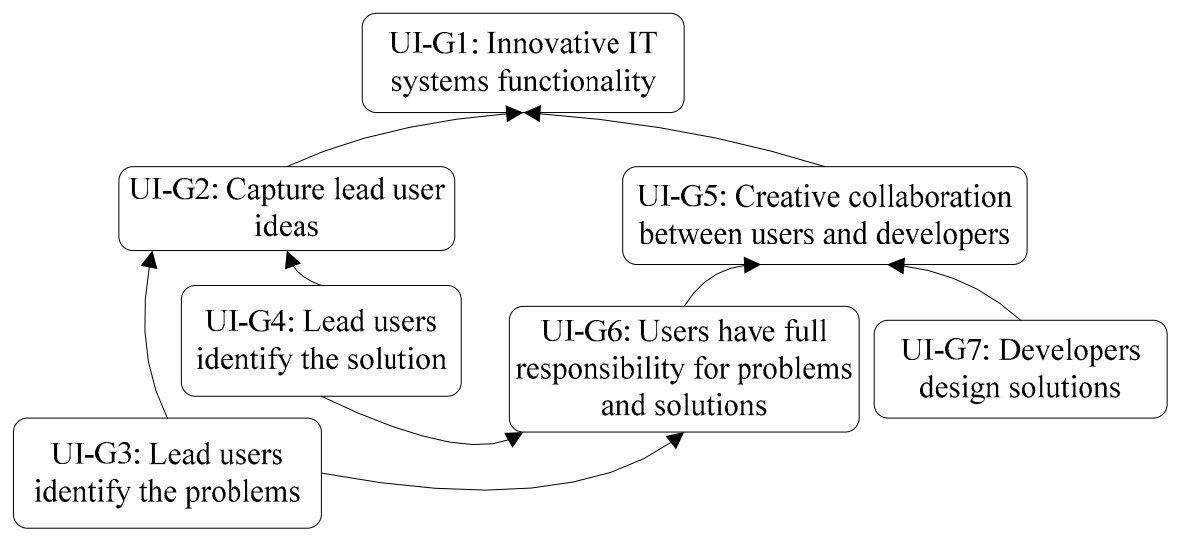

Fig. 4. Goal analysis for User Innovation

\section{Design Goal Challenges for User Participation}

We emphasize that user participation is important, and may provide beneficial results [3]. However, user participation approaches are associated with potential challenges that need to be addressed. In this Section, each approach is analyzed separately, using references to the goals in Fig. 2 to 4 and keywords from the five requirements in bold style.

\subsection{Challenges with Participatory Design}

PD aims for collaboration, and interactive development between developers and user representatives. The question is, however, how to create a development environment that emphasizes and encourages collaboration and interactivity. It is generally difficult to attract users to participate in e-service development, and even more difficult when the users are external. It is also difficult to ensure that all participants have sufficient knowledge and "speak the same language." Still, user participation is a must according to PD in order to develop relevant (PD-G3, PD-G4, PD-G7) and usable egovernment services (PD-G4, PD-G6) that support democratic processes (PD-G1).

Efficiency is a keyword for government, both concerning the resulting e-services and the development process itself (PD-G7). Using the e-service will only be efficient if the surrounding work processes are streamlined, often a neglected aspect. The systems development method requires a suitable set of method fragments selected for the situation, which in turn requires developers to critically review the potential method fragments. Basic skills and domain knowledge is imperative, but not given. Democracy (PD-G5) concerns how the government can communicate with the users and encourage them to put their opinions forward, as well as how to ensure participation across citizen groups in a democratic development process (PD-G3). The resulting e-service should foster inclusion of as many citizen groups as possible, and the risk is always that one or more groups feel left out. 


\subsection{Challenges with User Centered Design}

UCD aims to consider users and their environment during systems development. The user group is dispersed, which makes it difficult firstly to satisfy everyone's needs and thus make the e-services relevant (UCD-G4), and to find a language that enables communication about requirements and needs. Getting users to take on the advisory role is not trivial either. One question is thus how to attract potential advisors and how to acquire knowledge from users. A related challenge concerns usability of the eservices (UCD-G2, UCD-G4), in particular when developing an interface that supports all citizen groups.

Much like PD, efficiency in both e-services and the development process is difficult and requires the right tools (UCD-G5). Work processes must be identified and adjusted, but this is often a sensitive process. There are also great demands on the developers, since they must know not only the application environment, but also the users and their needs since the these are not active themselves during development. UCD also shares the challenges when working with democratic principles as PD does (UCD-G4, UCD-G5).

\subsection{Challenges with User Innovation}

UI is focused on the users being the driving force in development. The most difficult problem is to identify lead users in society. It is only then that lead user ideas can be captured, which affects relevance of the e-government services (UI-G2). However, these users should also want and have time to participate in and even lead egovernment service development. Furthermore, it is difficult to identify what a lead user $i s$ in a particular situation, and also what is required by that user. Regardless of user innovativeness, can they speak for the entire user (citizen) spectrum? The answer affects broad acceptance and usability of the solution (UI-G4). The e-services are intended for use within government organizations, and are hence also part of their work processes. Hence, can and should lead users judge how efficient (UI-G6, UI-G7) a solution is for the government organization. One main point in UI is that users drive the development process (UI-G6, UI-G7). It is not certain, however, that these users are experienced in developing e-government services, and they may therefore have problems expressing ideas and solutions.

Most users live in a world where democratic principles are important and drive the society. In this case, both the e-services (UI-G4) and the development process (UIG2) are concerned. Even so, lead users may firstly not be representative for the public in general, and there is no guarantee that their ideas and solutions put democratic principles before personal needs.

\section{Summarizing Analysis}

As Sections 5.1 to 5.3 express, one challenge is to identify a clear user target segment. PD is working with user representatives (PD-G3), UCD with user advisors (UCDG4), and UI builds on lead users (IU-G2). Hence, the users have to be representatives, advisors, or lead users for a larger group. However, demarcating such a target group is not easy. Many e-government services have to be offered more or less universally to 
all citizens [21]. Targeting "all" users in an entire population is a daunting task, which seems very hard to accomplish. In other words, one challenge is the dispersed target segment faced during development of e-government services.

All three approaches are also anchored in the assumption that individual users in the target group can be identified, and that these users can represent a larger user group (see for example PD-G3, UCD-G4, and UI-G2). However, most users are external, residing outside the governments organizational boundaries [41]. Consequently, it becomes more complicated to address appropriate users for participation in the development process, especially if we have to address individual citizens. A second challenge is, therefore, to identify individual users within the target segment.

The three user participation approaches range from active to passive participation. Both in PD and UI, the user is supposed to take active part in development (PD-G4, UI-G3, UI-G4), while in UCD, the user has a more passive role as advisor (UCD-G4). This means that the user often must be persuaded to participate and in the case of UI to have the ownership of the design (UI-G6). This is a major challenge, since the users most often are external to the government organization, and participation is based on free will. Internal users can be obliged to participate in development activities and may also see benefits with new functionality more clearly [42]. Accordingly, all three approaches have to face the challenge on how to attract external users to participate, where UI is the most demanding approach.

Development of e-government services is a complex endeavor. These artifacts often inherit a complex architecture from back-office systems, with a high number of relations and dependencies. This complexity is often invisible to the user and it is questionable to require that users should have such knowledge. When considering the design goals of our three approaches we see that they demands business knowledge to different degrees. Most demanding is UI, since the user is responsible for identifying the solution (UI-G6, IU-G7). In order to do that one is required to have extensive knowledge of what is possible to achieve. Least demanding is UCD, where the users have a more passive role and the developers have the business knowledge. Hence, skill inadequacy is the fourth challenge depending on the user's role in the design theories.

\section{Conclusions}

The importance of user involvement has been stressed in recent e-government research. Therefore, we have in this paper analyzed three user participation approaches, Participatory Design, User Centered Design and User Innovation, in egovernment service development from a goal perspective. In doing so, we identified four challenges when including users in development: (1) Identifying the user target segment, (2) Identifying the individual user within each segment, (3) Getting users to participate, and (4) Lacking adequate skills.

Traditionally, users have not been included in the e-government service development process [43]. However, e-presence and highlighted democratic principles that new technologies bring increase the need for government organizations to interact with citizens and enable their voices to be heard to a different extent than 
today. User participation generally produces better results in terms of, for example, more usable e-services. Government organizations should therefore be interested in adopting user participation in their e-government service development processes. They should also pay close attention to the challenges and allocate appropriate resources for dealing with them before they become problems.

The shift to user participation in e-government service development calls for future research into the structure and composition of a roadmap for said participation. For example, how shall ideas for new or improved services be captured? How shall ideas be prioritized and selected? And how can selected ideas be sufficiently detailed to allow for effective development? Our future research aims to develop a roadmap that is empirically grounded, and which is simple to adopt, use, and learn. It needs to be comprised of a set of methods fragments with concrete advice on how to apply them in an e-government service development setting. In this context, it is relevant to consider incorporating research on virtual or social communities, and in what way these phenomena alter or affect e-government service development.

\section{References}

1. Rowley, J.: An analysis of the e-service literature: towards a research agenda. Internet Research: Electronic Networking Applications and Policy 16, 879-897 (2006)

2. Asgarkhani, M.: The effectiveness of e-Service in Local Government: A Case Study. Electric journal of e-government 3, 157-166 (2005)

3. Melin, U., Axelsson, K., Lundsten, M.: Talking to, not about, Entrepreneurs - Experiences of Public e-service Development in a Business Start Up Case. In: Cunningham, P., Cunningham, M. (eds.) eChallanges, pp. 383-390 (2008)

4. Cavaye, A.L.M.: User participation is systems development revisited. Information and Management 28, 311-323 (1995)

5. Schuler, D., Namioka, A.: Participatory Design Priciples and Practicies - Preface. In: Schuler, D., Namioka, A. (eds.) Participatory Design Principles and Practicies, Lawrence Erlbaum Associates Inc., London (1993)

6. Norman, D.: Cognitive engineering. In: Norman, D. (ed.) User-Centered System Design: New Perspectives on Human Computer Interaction, pp. 31-65. Lawrence Erbaum Associated, London (1986)

7. Hippel, E.: Lead Users: A Source of Novel Product Concepts. Management Science 32, 791-805 (1986)

8. Hevner, A.R., March, S.T., Park, J., Ram, S.: Design Science in Information Systems Research. MIS Quarterly 28, 75-105 (2004)

9. Holmström, H.: Virtual Communities as Platforms for Product Development: An Interpretive Case Study of Customer Involvement in Online Game Developmen. In: International Conference on Information Systems 2001 (ICIS 2001), New Orleans, Louisiana, USA (2001)

10. Hansson, C., Dittrich, Y., Randall, D.: How to Include Users in the Development of Offthe-Shelf Software: A Case for Complementing Participatory Design with Agile Development. In: Annual Hawaii International Conference on System Sciences 2006 (HICSS 06), vol. 8. IEEE Computer Society, Los Alamitos (2006)

11. Gregor, S., Jones, D.: The Anatomy of a Design Theory. Journal of the Association of Information systems 8, 312-335 (2007) 
12. Friedman, K.: Theory construction in design research: criteria, approaches, and methods. Design Studies 24, 507-522 (2003)

13. Ågerfalk, P.J., Wistrand, K.: Systems Development Method Rationale: A Conceptual Framework for Analysis. In: Proceedings of the 5th International Conference on Enterprise Information Systems (ICEIS 2003), Angers, France (2003)

14. Harmsen, F.: Situational Method Engineering (1997)

15. Brinkkemper, S., Saeki, M., Harmsen, F.: Meta-Modelling based assembly techniques for situational method engineering. Information Systems 24, 209-228 (1999)

16. Brinkkemper, S.: Method engineering: engineering of information systems development methods and tools. Information and Software Technology 38, 275-280 (1996)

17. Jayratna, N.: Understanding and evaluating methodologies. McGraw-Hill, London (1994)

18. Yu, E.: Modeling Organizations for Information Systems Requirements Engineering. In: The IEEE International Symposium on Requirements Engineering, San Diego, USA (1993)

19. Klievink, B., Janssen, M.: Improving Integrated Service Delivery: A Simulation Game (2009)

20. Goldkuhl, G.: Socio-instrumental service modelling: An inquiry on e-services for tax declarations. In: Persson, A., Stirna, J. (eds.) PoEM 2009, vol. 39, pp. 207-221. Springer, Stockholm (2009)

21. Henriksen, Z.H.: The diffusion of e-services in Danish municipalities. In: Traunmüller, R. (ed.) EGOV 2004. LNCS, vol. 3183, pp. 164-171. Springer, Heidelberg (2004)

22. Lenk, K.: Electronic Service Delivery - A driver of public sector modernization. Information Polity 7, 87-96 (2002)

23. Layne, K., Lee, J.: Developing fully functional E-government: A four stage model. Government Information Quarterly 18, 122-136 (2001)

24. Cordella, A., Willcocks, L.: Outsourcing, bureaucracy and public value: Reappraising the notion of the "contract state". Government Information Quarterly 27, 82-88 (2010)

25. Odell, M., Hellberg, L.: Government Decision: Mission to initiate a project concerning a public ethos. Swedish Ministry of Finance (2009) (in Swedish)

26. Kangas, J., Store, R.: Internet and teledemocracy in participatory planning of natural resources management. Landscape and Urban Planning 62, 89-101 (2003)

27. Editorial Board. Government Information Quarterly 23, CO2-CO2 (2006)

28. Watson, R.T., Mundy, B.: A strategic perspective of electronic democracy. Communications of the ACM 44, 27-30 (2001)

29. Anthopoulos, L.G., Siozos, P.S., Tsoukalas, I.A.: Applying participatory design and collaboration in digital public services for discovering and re-designing e-Government services. Government Information Quarterly 24, 353-376 (2007)

30. Jupp, V.: Realizing the vision of e-government. In: Curtin, G., Sommer, M., Sommer-Vis, V. (eds.) The world of E-Government. Haworth Press (2003)

31. Lindblad-Gidlund, K.: Driver or Passenger? An analysis of Citizen-Driven eGovernment. In: Wimmer, M.A., Scholl, H.J., Ferro, E. (eds.) EGOV 2008. LNCS, vol. 5184, pp. 267-278. Springer, Heidelberg (2008)

32. Andersen, V.K., Medaglia, R.: eGovernment Front-End Services: Administrative and Citizen Cost Benefits. In: Wimmer, M.A., Scholl, H.J., Ferro, E. (eds.) EGOV 2008. LNCS, vol. 5184, pp. 148-159. Springer, Heidelberg (2008)

33. Carroll, J.M., Rosson, M.B.: Participatory design in community informatics. Design Studies 28, 243-261 (2007)

34. Muller, M.J., Kuhn, S.: Participatory design. Communications of the ACM 36, 24-28 (1993) 
35. Kensing, F., Blomberg, J.: Participatory design: Issues and Concerns. Computer Supported Cooperative work 7, 167-185 (1998)

36. Hooper, K.: Architectural design: An anology. In: Norman, D. (ed.) User-Centered System Design: New Perspectives on Human-Computer Interaction, pp. 9-23. Lawrence Erlbaum Associated, London (1986)

37. Bannon, L.: Issues in Design: Some Notes. In: User-Centered System Design: New Perspecives on Human-Computer Interaction, pp. 27-29. Lawrence Erlbaum, London (1986)

38. Noyes, J., Barber, C.: User-Centered design of systems. Springer, London (1999)

39. Hippel, E.: New Product Ideas from Lead Users. Research Technology Management 32, 24-27 (1989)

40. Herstatt, C., Hippel, E.: Developing New Product Concepts Via the Lead User Method: A Case Study in a "Low Tech Field". Journal of Product Innovation Management 9, 213-221 (1992)

41. Axelsson, K., Melin, U.: Citizen Participation and Involvement in eGovernment Projects An emergent framework. In: Wimmer, M.A., Scholl, H.J., Ferro, E. (eds.) EGOV 2008. LNCS, vol. 5184, pp. 207-218. Springer, Heidelberg (2008)

42. Albinsson, L., Forsgren, K.: Co-Design Metaphors and Scenarios - Two Elements in a Design Language for Co-Design. LAP, Kiruna (2005)

43. Axelsson, K., Melin, U.: Talking to, not about, citizens - Experiences of focus groups in public e-service development. In: Wimmer, M.A., Scholl, H.J., Grönlund, Å. (eds.) EGOV 2007. LNCS, vol. 4656, pp. 179-218. Springer, Heidelberg (2007) 